\title{
The Value of Ultrasound Elastography in Diffuse Thyroid Disease among a Sample of Iraqi Population
}

\author{
Lubna Ali Hussein ${ }^{1}$, Hiba Mohammed Abdulwahid ${ }^{2 *}$, Areege Mustafa Kamal ${ }^{3}$ \\ ${ }^{1}$ Department of Radiology, Kamal al-Samaraai Specialist Hospital, Baghdad, Iraq; ${ }^{2}$ Department of Radiology, College of Medicine, \\ University of Baghdad, Baghdad, Iraq; ${ }^{3}$ Department of Histopathology, Oncology Teaching Hospital, Medical City, Baghdad, Iraq
}

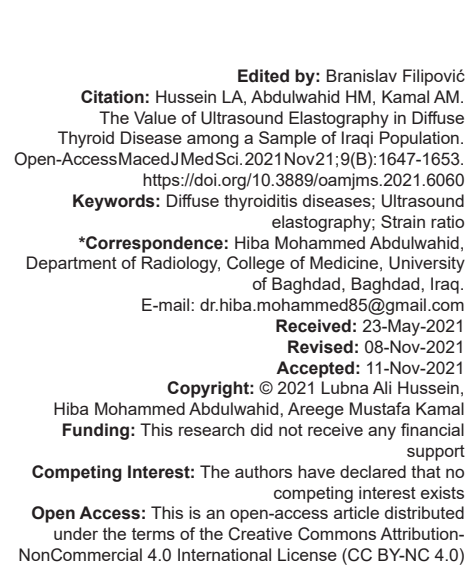

\section{Introduction}

Diffuse thyroid disease (DTD) is a major etiology of thyroid dysfunction, and the early recognition of subclinical DTD can be useful in the proper management of the associated thyroid dysfunction [1]. DTDs include chronic autoimmune hypothyroidism (Hashimoto's thyroiditis [HT]), hyperthyroidism (Graves' disease [GD]), and subacute thyroiditis (SAT). Although the biochemical, clinical, and sonographic features of DTDs are similar, their etiopathogeneses are different and need different managements. Ultrasound (US) can distinguish DTD (thyroiditis) from normal thyroid gland but it has a limited role in the characterization of the types of thyroiditis. Hence, more advanced radiological techniques have to be developed to give important useful information that are needed when planning management [2].

US elastography (USE) is an US technique used to evaluate the biomechanical features of tissue in the medical practice. USE has different types, the first type to be introduced was strain USE and it is dependent on the principle that, when compression is applied, the softer parts of tissues deform easier than the harder parts [3]. As the histopathologic and mechanical characteristics are different, it is possible to distinguish GD from HT and SAT by USE [4]. SAT is a self-limiting disorder that generally occurs due to an autoimmune response after upper tract infection that caused by a viral etiology [5]. In the early stage of SAT, inflamed tissues lose elasticity due to fibrotic changes and revealed significant abnormality on USE [6]. HT is the most common inflammatory condition of the thyroid gland and is the main cause of hypothyroidism [7]. The degree of the fibrotic changes of thyroid parenchyma is correlated with the increased hardness and stiffness in $\mathrm{HT}$ that can be evaluated by elastography [8]. Chronic non-specific thyroiditis is a non-suppurative thyroiditis of unidentified cause, both men and women may be affected in any age. It is an autoimmune disorder that is not fulfilling the criteria for diagnosis of HT and GD [9]. It is characterized by the rapid change in the texture of the gland with the development of fixed hard gland without signs of hyperthyroidism or hypothyroidism, although a goiter may be present.

\section{Aim of study}

This study aims to assess the role of US strain elastography in the diagnosis of diffuse non-nodular thyroid disease in comparison to healthy controls and 
in the characterization and distinguishing the types of DTDs from each other.

\section{Patients and Methods}

\section{Study design and settings}

It is a prospective analytic study that performed in the Radiology Department of Oncology Teaching Hospital/Medical city in Baghdad from December 1, 2019, to June 30, 2020.

\section{Study population}

Patients referred from the surgical or endocrine outpatient clinics to the Radiology Department of Oncology Teaching Hospital with suspected thyroid gland disease and were compared with standard healthy control group with normal thyroid gland on US and normal thyroid function test.

\section{Inclusion criteria}

Patients with non-nodular DTD with or without symptoms of hypothyroidism or hyperthyroidism were included in the study.

\section{Exclusion criteria}

The following criteria were excluded from the study:

1. Patients with a previous history of thyroid surgery

2. Patients who received neck radiation therapy

3. Pregnant women

4. Patient received medication as part of management of DTD.

\section{Sampling}

The study sample included 25 patients with DTD presented to the Radiology Department of Oncology Teaching Hospital and selected according to the inclusion and exclusion criteria after their approval, in addition to a sample of 25 healthy controls for comparison.

\section{Data collection}

Clinical data were taken from patients and involved the followings.

1. Demographic characteristics of the patients: Age and gender

2. Hormonal laboratory results of patients with DTD: Euthyroid, hypothyroidism, and hyperthyroidism
3.

4.

4. US findings of the patients (texture, echogenicity, AP diameter of thyroid gland, and vascularity)

5. Elastography findings (strain ratio).

\section{Patients assessment}

The diagnosis of DTD was made by combination of clinical symptoms, laboratory investigations, and thyroid US. The DTD was classified according to clinical symptoms, hormonal investigation (thyroid function test including T3, T4, and TSH), and immunological investigation (thyroid peroxidase antibody level) into GD, HT, and SAT. Patients with DTD that could not be classified into Graves, Hashimoto's, or SAT, according to their clinical and laboratory investigation, were considered to have non-specific thyroiditis. Fineneedle aspiration (FNA) cytology was performed for eight patients according to the physician request and to confirm the diagnosis in those patients. The FNA was done by a senior pathologist in the oncology teaching hospital, and the results were consistent with the classified type of DTD in those patients and confirmed it.

The thyroid US was performed by radiology specialist using GE healthcare machine 2019 LOGIQ S8 XDclear with linear probe (Matrix Probe ML6-15-RD). The parameters on B-mode US were included: Thyroid parenchymal echogenicity (echogenicity was classified into hypoechoic, isoechoic, or hyperechoic as compared with adjacent strap muscles), texture (homogenous or heterogeneous), vascularity of the thyroid parenchyma which was classified into normal, hypervascular and markedly hypervascular (thyroid inferno), the vascularity was classified in comparison with normal thyroid gland vascularity in control group. Thyroid size (which is calculated by the formula of thyroid lobe volume: Length $\times$ width $\times$ depth in $\mathrm{cm} \times 0.5$ ) excluding the isthmus. The volume of thyroid gland was the sum of the volume of both lobes. The size was classified into enlarged, normal and small size "atrophic" according to the normal range of thyroid volume $(8-20 \mathrm{ml})$. Then, strain elastography was performed by putting the elastography square box on the thyroid gland including most of the thyroid tissue with the ipsilateral muscles within the box. Very gentle compression was applied on the thyroid tissue while asking the patients to hold breath and swallowing during elastography procedure to avoid artifact and misinterpretation. The optimal compression was achieved when the vertical bar on the upper left side of the image was filled with the green color. Method of measurement of strain ratio is demonstrated in Figure 1.

The five colors grading in elastography was not assessed in this study as it has limited role in DTD, in contrast to thyroid nodule, but the semi-quantitative measurements were obtained. Two regions of interest 


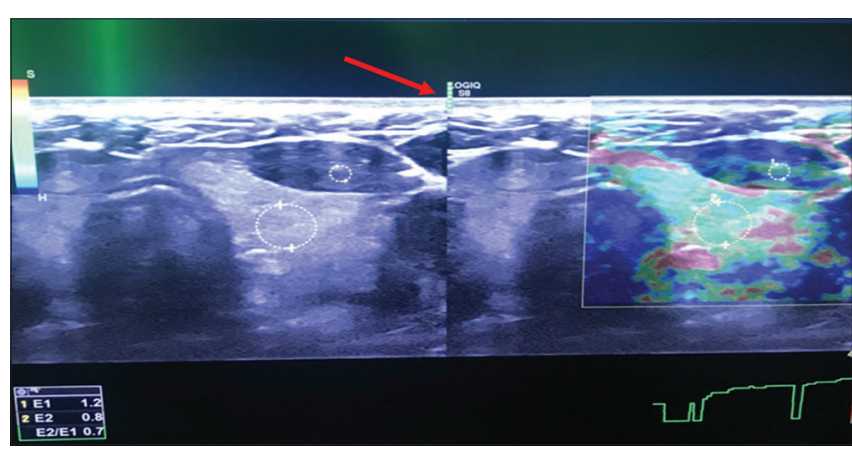

Figure 1: Method of measuring $S R$ in control subject with normal thyroid gland in B-mode ultrasound (US) and normal thyroid function test. Two ROIs were selected to calculate the strain ratio, one circle is on the strap muscle and the 2nd circle (2nd ROI) on the ipsilateral thyroid tissue. US strain elastography ratio was 0.7 . Note that the vertical bar is filled with the green color in the upper left side of the image (red arrow)

were taken; one on the adjacent strap muscle as standard reference and the other on the abnormal thyroid tissue then the US machine calculates the strain ratio automatically. The above-mentioned parameters in B-mode US and elastography were assessed and registered in both patients with DTD and control group.

\section{Ethical considerations}

1. The approval was taken from Radiology Scientific Committee of Baghdad Medical College

2. A written informed consent was taken from all patients.

\section{Statistical analysis}

All patients' data are tabulated using computerized statistical software; that is, Statistical Package for the Social Sciences version 20. Descriptive statistics obtained as mean \pm standard deviation and the frequencies presented as percentages. Comparison between categorical variables was performed using Chi-square test (and Fisher's exact test was performed when the total of predictable variables being $<20 \%$ of the total). Comparison between two means was done by independent sample t-test and comparison between more than 2 means was done by one-way ANOVA analysis. Receiver operating characteristic (ROC) curve was used to predict the appropriate cutoff value and the best validity of different strain ratios in prediction of DTD. The level of significance (i.e., p-value) established at $\leq 0.05$ in all the statistical analysis, and the result was presented as tables and/or graphs. A community medicine specialist had done the statistical analysis of the study.

\section{Results}

\section{Demographic data of the patients}

This study included 25 patients with DTD presented with the mean age of $42.1 \pm 12.3$ years; most of the patients $(32 \%)$ were in the age group of 40-49 years, other age groups are shown in Figure 2.

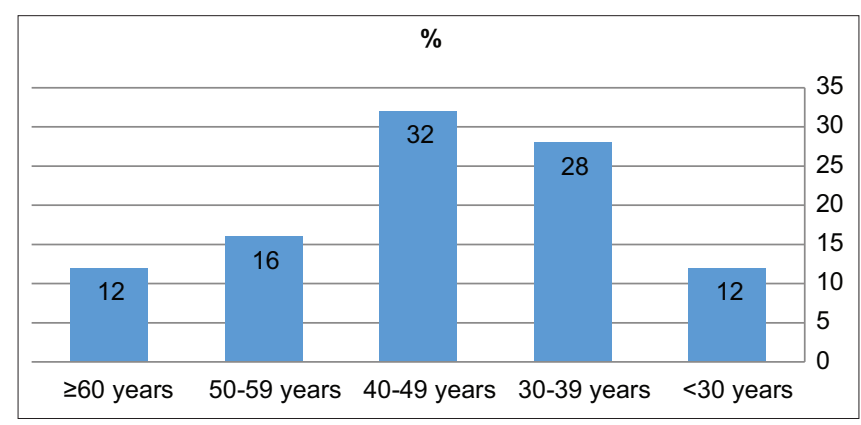

Figure 2: Distribution of patients with diffuse thyroid disease according to their age groups

Regarding gender, female gender patients with DTD were more than male gender patients with femaleto-male ratio as 5.2:1. These findings are demonstrated in Figure 3.

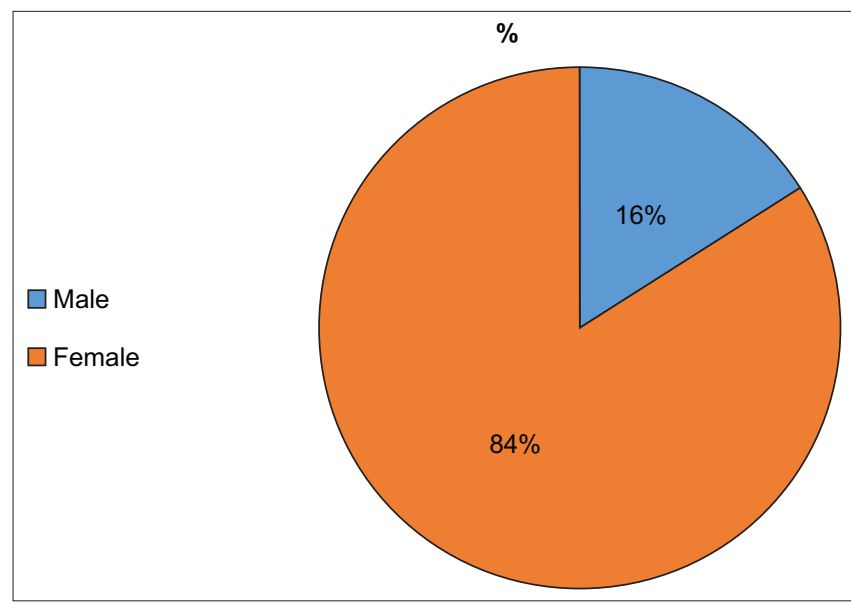

Figure 3: Gender distribution of patients with diffuse thyroid disease

\section{The hormonal status and the types of DTD}

The hormonal status of patients with DTD in this study was classified into euthyroid (12\%), hypothyroidism (40\%), and hyperthyroidism (48\%).

The classification of patients with DTD, which was based on clinical history, hormonal and immunological investigation followed by FNA for eight patients, showed that $44 \%$ of them had $\mathrm{HT}, 44 \%$ of them had GD, $8 \%$ of them had non-specific thyroidism and $4 \%$ of them had SAT.

\section{B-mode US characteristics of DTD}

The US examination revealed that $92 \%$ of patients with DTD had heterogeneous parenchymal 
texture, while $8 \%$ of them had homogenous texture. Hypoechoic thyroid parenchyma was detected for $84 \%$ of patients with DTD and $16 \%$ had hyperechoic parenchyma. Regarding the size of thyroid gland, $52 \%$ of patients with DTD had enlarged gland, $36 \%$ had normal sized gland, and $12 \%$ had atrophic gland. Regarding vascularity, $16 \%$ of DTD patients had normal vascularity, $72 \%$ of them had hypervascularity, and $12 \%$ of them had marked hypervascularity (thyroid inferno). The mean elastography strain ratio of patients with DTD was $1.3 \pm 0.6$. All these findings are illustrated in Table 1.

Table 1: B-mode US characteristics of patients with DTD

\begin{tabular}{|c|c|c|}
\hline US parameters & $\mathrm{N}$ & $\%$ \\
\hline \multicolumn{3}{|l|}{ Texture } \\
\hline Heterogeneous & 23 & 92.0 \\
\hline Homogenous & 2 & 8.0 \\
\hline Total & 25 & 100.0 \\
\hline \multicolumn{3}{|l|}{ Echogenicity } \\
\hline Hypoechoic & 21 & 84.0 \\
\hline Hyperechoic & 4 & 16.0 \\
\hline Total & 25 & 100.0 \\
\hline \multicolumn{3}{|l|}{ Size } \\
\hline Enlarged & 13 & 52.0 \\
\hline Normal & 9 & 36.0 \\
\hline Small & 3 & 12.0 \\
\hline Total & 25 & 100.0 \\
\hline \multicolumn{3}{|l|}{ Vascularity } \\
\hline Normal & 4 & 16.0 \\
\hline Hypervascular & 18 & 72.0 \\
\hline Markedly hypervascular & 3 & 12.0 \\
\hline Total & 25 & 100.0 \\
\hline
\end{tabular}

Highly significant association was observed between heterogeneous thyroid texture and patients with DTD ( $p<0.001) ; 92 \%$ of patients with DTD had heterogeneous parenchymal texture, while no healthy control had heterogeneous thyroid texture. All these findings are demonstrated in Table 2.

Table 2: Distribution of thyroid parenchymal texture on B-mode US according to study groups

\begin{tabular}{|c|c|c|c|c|c|}
\hline \multirow[t]{2}{*}{ Variable } & \multicolumn{2}{|c|}{ DTD cases } & \multicolumn{2}{|c|}{ Controls } & \multirow[t]{2}{*}{$\mathrm{p}$} \\
\hline & $\mathrm{N}$ & $\%$ & $\mathrm{~N}$ & $\%$ & \\
\hline \multicolumn{6}{|c|}{ Thyroid texture on B-mode US } \\
\hline Heterogeneous & 23 & 92.0 & 0 & - & $<0.001^{* \mathrm{~s}}$ \\
\hline Homogenous & 2 & 8.0 & 25 & 100.0 & \\
\hline
\end{tabular}

US: Ultrasound, DTD: Diffuse thyroid disease.

\section{The elastography strain ratio} study groups

Elastography strain ratio according to the

The mean elastography strain ratio (1.36) of patients with DTD was significantly higher than $(0.82)$ mean of elastography strain ratio for healthy controls $(p<0.001)$. All these findings are illustrated in Table 3.

The acceptable cutoff values and the equivalent validity results for elastography strain ratio in the estimation of DTD are demonstrated in Table 4, the

Table 3: Distribution of elastography strain ratio according to study groups

\begin{tabular}{|c|c|c|c|}
\hline \multirow[t]{2}{*}{ Variable } & DTD cases & Controls & \multirow{2}{*}{$\mathrm{p}$} \\
\hline & Mean \pm SD & Mean \pm SD & \\
\hline Elastography strain ratio & $1.3 \pm 0.6$ & $0.82 \pm 0.13$ & $<0.001^{\star^{5}}$ \\
\hline
\end{tabular}

cutoff elastography strain ratio of 0.89 had acceptable validity results $(80 \%$ sensitivity, $70 \%$ specificity, $70.2 \%$ positive predictive value (PPV), $82.5 \%$ negative predictive value (NPV), and accuracy $75 \%$ ).

Table 4: ROC coordinates for the prediction of DTD by elastography strain ratio

\begin{tabular}{llllll}
\hline Cutoff point & Sensitivity (\%) & Specificity (\%) & PPV (\%) & NPV (\%) & Accuracy (\%) \\
\hline 0.77 & 90 & 43.3 & 42.8 & 83.4 & 66 \\
0.89 & 80 & 72 & 70.2 & 82.5 & 75 \\
1.01 & 66.7 & 86.7 & 88.8 & 63 & 70.2 \\
\hline DTD: Diffuse thyroid disease, NPV: Negative predictive value, PPV: Positive predictive value.
\end{tabular}

DTD: Diffuse thyroid disease, NPV: Negative predictive value, PPV: Positive predictive value.

\section{types of DTD \\ Elastography strain ratio according to the}

The mean elastography strain ratio was significantly increased among patients with SAT (increased tissue stiffness), while significantly lower among patients with non-specific thyroiditis $(p<0.001)$, as demonstrated in Table 5.

Table 5: Distribution of elastography strain ratio for patients with DTD according to the types of DTD

\begin{tabular}{|c|c|c|c|c|c|}
\hline \multirow[t]{2}{*}{ Variable } & Non-specific T. & $\overline{\mathrm{HT}}$ & GD & SAT & \multirow[t]{2}{*}{$\mathrm{p}$} \\
\hline & Mean \pm SD & Mean \pm SD & Mean \pm SD & Mean \pm SD & \\
\hline $\begin{array}{l}\text { Elastography } \\
\text { strain ratio }\end{array}$ & $0.9 \pm 0.4$ & $1.47 \pm 0.4$ & $0.98 \pm 0.2$ & $3.5 \pm 0.0$ & $<0.001^{* S}$ \\
\hline
\end{tabular}

As shown in Table 6, the mean elastography strain ratio for patients with HT was significantly higher than strain ratio of patients with GD $(p=0.002)(H T$ reduced elasticity and increased stiffness of thyroid tissue greatly more than GD).

Table 6: Distribution of elastography strain ratio for patients with $\mathrm{HT}$ and GD

\begin{tabular}{llll}
\hline Variable & Hashimoto's T & GD & $\mathrm{p}$ \\
\cline { 2 - 3 } & Mean \pm SD & Mean \pm SD & \\
\hline Elastography strain ratio & $1.47 \pm 0.4$ & $0.98 \pm 0.2$ & $0.002^{* S}$ \\
\hline
\end{tabular}

*Independent sample t-test, S: Significant, HT: Hashimoto's thyroiditis, GD: Graves' disease.

And so, differentiation between the types of the DTD was achieved using strain elastography while these types cannot be differentiated by B-mode US alone.

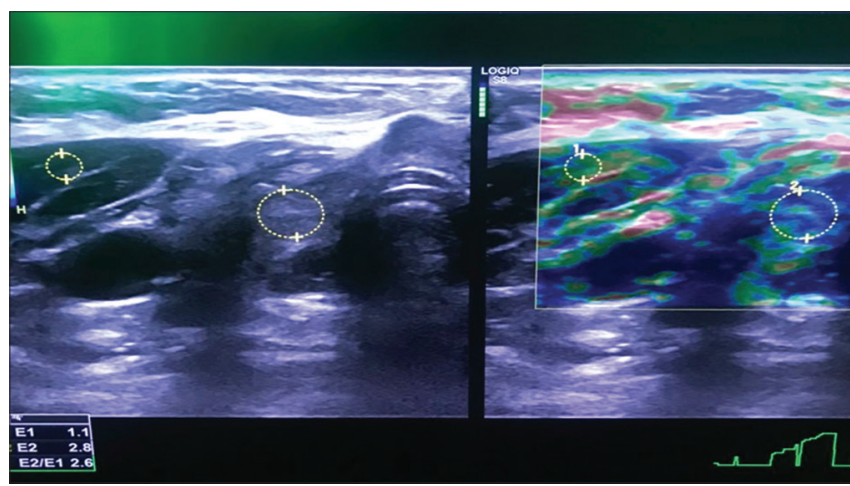

Figure 4: A 35-year-old female presented with symptoms of hypothyroidism and diagnosed with Hashimoto's thyroiditis according to hormonal and immunological investigation. B-mode ultrasound had showed heterogeneous hyperechoic thyroid parenchyma suggestive of diffuse thyroid disease. Strain elastography ratio was 2.6 


\section{Discussion}

The USE is a common non-invasive imaging technique for the evaluation of thyroid dysfunction as it could be applied in the assessment of mechanical characteristics for elasticity of different tissues. Despite that, there are different pathological abnormalities that are accompanied with an appropriate elastography which are not detected till now [10]. In general, the benefits of USE in thyroid disease are proved [6].

The HT is the most common cause of goiter in Iraq [11]. This study is the first Iraqi study discussing the role of strain elastography in the evaluation and characterization of DTD. The present study revealed that mean elastography strain ratio was significantly higher in patients with DTD than the mean elastography strain ratio for healthy controls $(p<0.001)$ (i.e., all DTDs increased tissue stiffness as compared with healthy controls). These results are consistent with results of Yang et al. study in China which found that strain ratio of patients with diffuse thyroiditis was significantly higher than strain ratio of healthy controls [12]. Many authors reported the importance of USE in the evaluation of DTDs [13], [14].

In Turkey, Menzilcioglu et al. study on 31 randomized patients showed that strain elastography ratio was dependable findings and patients with $\mathrm{HT}$ had mean ratio of $1.39+0.72$ while strain ratio of healthy controls was $0.76+0.55$ [15]. The US strain elastography was shown a great role in detecting alterations in the viscoelasticity by recording the degree of stiffness of thyroid parenchyma [12]. In addition, the US of tissue textures is analyzed before and after compression of the tissues and difference between the two signals refers to the strain value [12]. The fibrosis and lymphocytic infiltration of thyroid gland of DTD increase the stiffness and hardness of the thyroid tissue [16].

Our study showed that acceptable cutoff elastography strain ratio was 0.89 with validity results $(80 \%$ sensitivity, $70 \%$ specificity, and $75 \%$ accuracy) in the characterization of DTD. These results are similar to the results of Çekiç et al. study in Turkey which found that appropriate cutoff value for strain ratio in differentiation between patients with $\mathrm{HT}$ than healthy controls was 0.98 with validity findings ( $83 \%$ sensitivity, $93 \%$ specificity, and $84 \%$ accuracy) [17].

The present study revealed a highly significant association between heterogeneous thyroid texture and patients with diffuse thyroiditis $(p<0.001)$. This finding is similar to the results of many previous literatures which stated that heterogeneous texture of thyroid gland is accompanying mostly the DTD mainly HT and GD [18], [19], [20], [21]. However, Park et al. study in South Korea found that the heterogeneity of the thyroid gland is always responsible for reducing the specificity and accuracy of US in differentiation between malignant and benign thyroid nodules in DTD [22]. Despite this finding, abnormal US appearance of thyroid gland is useful in diagnosis of diffuse thyroid disorders in asymptomatic persons [23], [24] and also helpful in the early detection and diagnosis of subclinical to overt hypothyroidism in combination with thyroid antibodies [25], [26]. Moreover, the US of thyroid gland is important in the prediction of treatment outcomes for patients with subclinical hypothyroidism [26].

In the present study, the mean elastography strain ratio was significantly high among patients with SAT which is explained by the fibrotic changes that markedly increased the stiffness of the gland tissue, while the strain ratio was significantly lower among patients with non-specific thyroiditis $(p<0.001)$. These results are in agreement with the results of Korkmaz et al. study in Turkey on 24 patients with GD, 94 patients with $\mathrm{HT}, 20$ patients with SAT, and 82 healthy controls and found that the mean elastography strain ratio was significantly higher in patients with SAT than the mean elastography strain ratio of patients with $\mathrm{GD}, \mathrm{HT}$, and healthy controls [2]. Another study carried out in Poland by Ruchala et al. revealed that the sonoelastography is useful in the diagnosis and monitoring of SAT in addition to the differentiation between the variable types of diffuse thyroiditis [6]. The elastography is known as an electronic palpation for thyroid gland that is required in differentiation between different types of thyroid diseases depending on strain ratio and shear wave elastography [27].

In the current study, the mean elastography strain ratio for patients with HT was significantly higher than the strain elastography ratio of patients with GD $(p=0.002)$. These results coincide with the results of many previous literatures such as Menzilcioglu et al. [28] study in Turkey and Yang et al. [12] study in China which found that the mean elastography strain ratio for HT was higher than the strain ratio of GD. In Italy, Cantisani et al. [29] study reported that the elastography strain ratio had an interesting role in the differentiation between HT and GD as the strain ratio was higher among patients with $\mathrm{HT}$. Both HT and GD are autoimmune diseases of thyroid gland. The differentiation between both diseases might be somewhat difficult by clinical and laboratory findings [30]. The present study revealed that the B-mode US can detect DTD but cannot differentiate its types of in most patients due to the similarity in US parameters for all types of DTD. A current study conducted by Pishdad et al. in Iran [31] found that US examination had low sensitivity in the differentiation between HT and GD due to the marked similarity in the sonographic appearance and needed the elastography for increasing effectiveness of differentiation particularly by shear wave elastography, strain ratio, and acoustic radiation force impulse [32]. 


\section{Conclusions}

- The USE is a non-invasive imaging technique that is useful in the evaluation and characterization of DTD by the assessment of the changes in the tissue elasticity/stiffness caused by different types of DTD as compared with normal subjects (non-specific thyroiditis and $\mathrm{HT}$ reducing the tissue elasticity/increase stiffness significantly more than GD and SAT) The USE strain ratio value is helpful in the evaluation of DTDs with acceptable validity findings

- The USE strain ratio value is helpful in differentiation between the different DTDs, especially between HT and GD.

\section{References}

1. Ahn HS, Kim DW, Lee YJ, Baek HJ, Ryu JH. Diagnostic accuracy of real-time sonography in differentiating diffuse thyroid disease from normal thyroid parenchyma: A multicenter study. AJR Am J Roentgenol. 2018;211(3):649-54. https://doi.org/10.2214/ ajr.17.19164

PMid:29995502

2. Korkmaz AA, Baki G, Kose M, Cobanoglu YB. Value of real-time and strain ratio elastography in differential diagnosis of graves' disease and subacute and hashimoto's thyroiditis. Iran J Radiol. 2017;14(4):e22019. https://doi.org/10.5812/iranjradiol.22019

3. Garra BS. Elastography: Current status, future prospects, and making it work for you. Ultrasound Quart. 2011;27(3):177-86. https://doi.org/10.1097/ruq.0b013e31822a2138 PMid:21873855

4. Bogazzi F, Bartalena L, Brogioni S, Burelli A, Manetti L, Tanda ML, et al. Thyroid vascularity and blood flow are not dependent on serum thyroid hormone levels: Studies in vivo by color flow Doppler sonography. Eur J Endocrinol. 2005;140(5):452-6. https://doi.org/10.1530/eje.0.1400452

PMid:10229913

5. Omori N, Omori K, Takano K. Association of the ultrasonographic findings of subacute thyroiditis with thyroid pain and laboratory findings. Endocr J. 2008;55(3):583-8. https://doi.org/10.1507/ endocrj.k07e-163

PMid:18490832

6. Ruchala M, Szczepanek-Parulska E, Zybek A, Moczko J, Czarnywojtek A, Kaminski G, et al. The role of sonoelastography in acute, subacute and chronic thyroiditis: A novel application of the method. Eur J Endocrinol. 2012;166:425-32. https://doi. org/10.1530/eje-11-0736

PMid:22143319

7. Anderson L, Middleton WD, Teefey SA, Reading CC, Langer JE, Desser $\mathrm{T}$, et al. Hashimoto thyroiditis: Part 2, sonographic analysis of benign and malignant nodules in patients with diffuse Hashimoto thyroiditis. AJR Am J Roentgenol. 2010;195(1):216-22. https://doi.org/10.2214/ajr.09.3680 PMid:20566819

8. Sporea I, Vlad M, Bota S, Sirli RL, Popescu A, Danila M, et al. Thyroid stiffness assessment by acoustic radiation force impulse elastography (ARFI). Ultraschall Med. 2011;32(3):281-5. https:// doi.org/10.1055/s-0029-1246048

PMid:21321841

9. Lee JG. Chronic nonspecific thyroiditis. Arch Surg 1935;31(6):982-1012.

10. Zhao $\mathrm{CK}, \mathrm{Xu} \mathrm{HX}$. Ultrasound elastography of the thyroid: Principles and current status. Ultrasonography. 2019;38(2):106-24. https://doi.org/10.14366/usg.18037 PMid:30690960

11. Al-Hashimi AM. Hashimoto's thyroiditis: A personal experience. QMJ. 2014;10(17):248-52.

12. Yang Z, Zhang $H$, Wang $K$, Cui G, Fu F. Assessment of diffuse thyroid disease by strain ratio in ultrasound elastography. Ultrasound Med Biol. 2015;41(11):2884-9. https://doi. org/10.1016/j.ultrasmedbio.2015.07.012

PMid:26306430

13. Dighe $M$, Bae $U$, Richardson ML, Dubinsky TJ, Minoshima $S$, Kim Y. Differential diagnosis of thyroid nodules with US elastography using carotid artery pulsation. Radiology. 2008;248:662-9. https://doi.org/10.1148/radiol.2482071758 PMid: 18539888

14. Vorländer $\mathrm{C}$, Wolff J, Saalabian $\mathrm{S}$, Lienenlüke RH, Wahl RA Real-time ultrasound elastography--a noninvasive diagnostic procedure for evaluating dominant thyroid nodules. Langenbecks Arch Surg. 2010;395(7):865-71. https://doi. org/10.1007/s00423-010-0685-3 PMid:20632029

15. Menzilcioglu MS, Duymus M, Gungor G, Citil S, Sahin T, Boysan SN, et al. The value of real-time ultrasound elastography in chronic autoimmune thyroiditis. $\mathrm{Br} \mathrm{J}$ Radiol. 2014;87(1044):20140604. https://doi.org/10.1259/bjr.20140604 PMid:25315887

16. Cantisani V, Lodise P, Grazhdani H, Mancuso E, Maggini E, Di Rocco G, et al. Ultrasound elastography in the evaluation of thyroid pathology. Current status. Eur J Radiol. 2014;83(3):420-8. https://doi.org/10.1016/j.ejrad.2013.05.008 PMid:23763859

17. Çekiç B, Parlak AE, Koksel Y, Toslak IE, Parlak M. Real-time ultrasound elastography evaluation of the thyroid gland in adolescent patients with hashimoto thyroiditis. Biomed Res. 2017;28(17):7534-9.

18. Marcocci C, Vitti P, Cetani F, Catalano F, Concetti $R$, Pinchera A. Thyroid ultrasonography helps to identify patients with diffuse lymphocytic thyroiditis who are prone to develop hypothyroidism. J Clin Endocrinol Metab. 1991;72(1):209-13. https://doi.org/10.1210/jcem-72-1-209

PMid:1986019

19. Ohmori N, Miyakawa M, Ohmori K, Takano K. Ultrasonographic findings of papillary thyroid carcinoma with Hashimoto's thyroiditis. Intern Med. 2007;46(9):547-50. https://doi. org/10.2169/internalmedicine.46.1901 PMid: 17473486

20. Set PA, Oleszczuk-Raschke $\mathrm{K}$, von Lengerke JH, Bramswig J. Sonographic features of Hashimoto thyroiditis in childhood. Clin Radiol. 1996;51(3):167-9. https://doi.org/10.1016/ s0009-9260(96)80317-5

PMid:8605745

21. Singh B, Shaha AR, Trivedi H, Carew JF, Poluri A, Shah JP. Coexistent Hashimoto's thyroiditis with papillary thyroid carcinoma: Impact on presentation, management, and outcome. Surgery. 1999;126(6):1070-6. https://doi.org/10.1067/ msy.2099.101431

PMid:10598190

22. Park M, Park SH, Kim EK, Yoon JH, Moon HJ, Lee HS, et al. Heterogeneous echogenicity of the underlying 
thyroid parenchyma: How does this affect the analysis of a thyroid nodule? BMC Cancer. 2013;13:550. https://doi. org/10.1186/1471-2407-13-550

PMid:24237991

23. Kwak JY, Han KH, Yoon JH, Moon HJ, Son EJ, Park SH, et al. Thyroid imaging reporting and data system for US features of nodules: A step in establishing better stratification of cancer risk. Radiology. 2011;260(3):892-9. https://doi.org/10.1148/ radiol. 11110206

PMid:21771959

24. Kwak JY, Koo H, Youk JH, Kim MJ, Moon HJ, Son EJ, et al. Value of US correlation of a thyroid nodule with initially benign cytologic results. Radiology. 2010;254(1):292-300. https://doi. org/10.1148/radiol.2541090460

25. Rosário PW, Bessa B, Valadão MM, Purisch S. Natural history of mild subclinical hypothyroidism: Prognostic value of ultrasound. Thyroid. 2009;19(1):9-12. https://doi.org/10.1089/thy.2008.0221 PMid:19021461

26. Shin D, Kim E, Lee E. Role of ultrasonography in outcome prediction in subclinical hypothyroid patients treated with levothyroxine. Endocr J. 2010;57(1):15. https://doi.org/10.1507/ endocrj.k09e-154

PMid:19823000

27. Gietka-Czernel M, Kochman M, Bujalska K, StachlewskaNasfeter E, Zgliczynski W. Real-time ultrasound elastography-a new tool for diagnosing thyroid nodules.
Endokrynol Pol. 2010;61(6):652-7.

PMid:21104638

28. Menzilcioglu MS, Duymus M, Avcu S. Sonographic elastography of the thyroid gland. Pol J Radiol. 2016;81:152-6. https://doi. org/10.12659/pjr.896178

PMid:27103947

29. Cantisani V, Grazhdani H, Drakonaki E, D'Andrea V, Di Segni M, Kaleshi E, et al. Elastography for the characterization of thyroid nodules: Advantages and limitation. Int $\mathrm{J}$ Endocrinol. 2015;2015:908575. https://doi.org/10.1155/2015/908575 PMid:25954310

30. Iddah MA, Macharia BN. Autoimmune thyroid disorders ISRN Endocrinol. 2013;2013:509764. https://doi org/10.1155/2013/509764

PMid:23878745

31. Pishdad P, Pishdad GR, Tavanaa S, Pishdad R, Jalli R. Thyroid ultrasonography in differentiation between graves' disease and hashimoto's thyroiditis. J Biomed Phys Eng. 2017;7:21-6. https://doi.org/10.1089/thy.2010.0386

PMid:28451576

32. Hefeda MM. Value of the new elastography technique using acoustic radiation force impulse in differentiation between Hashimoto's thyroiditis and Graves' disease. J Clin Imaging Sci. 2019;9:17. https://doi.org/10.25259/jcis-22-2019

PMid:31448168 